\title{
Industrial Metabolism Analysis and Green Optimization of a Painting Production Line
}

\author{
Lai Wenjie ${ }^{1, *}$ \\ ${ }^{1}$ School of management of Tianjin University of Technology, research Centerior circular economy and sustainable development of \\ enterprises, Tianjin 300384
}

\begin{abstract}
This article takes a coating production line as an example, uses industrial metabolism analysis method to quantitatively analyse its material metabolism process, and forms a material balance sheet to evaluate resource efficiency and environmental efficiency. The results show that the resource efficiency of the coating production line is $0.4 \%$, and the environmental efficiency is $0.51 \%$, indicating that there is a serious waste of resources and greater environmental pressure. The reason is the old spraying method, the use of highly volatile paints and cleaning agents, and the higher VOC content of the paint. In response to these problems, this article combines the input and output content of the production line and proposes several green optimization approaches from the perspectives of cleaner production, circular economy and ecological industrial parks.
\end{abstract}

\section{Introduction}

Coating is an important part of modern manufacturing process. Through basic processes such as surface treatment, coating process and drying of the product, it can effectively prevent rust, corrosion and beautification of mechanical products. It is currently widely used in home appliances, machine tools, Electronics, aerospace and other fields. However, while the coating process assists the modern manufacturing process, it also brings a large degree of environmental hazards. For example, smog is a major environmental problem that plagues the country's development. VOC is one of the main factors in its formation, and the painting industry is the main source of VOC emissions. Therefore, in order to control smog, environmental protection departments at all levels have successively issued relevant measures to suppress VOC. Mandatory measures for emissions. At present, most processes are end treatment, which achieves emission reduction through activated carbon adsorption and catalytic combustion. Although the catalytic combustion technology can efficiently treat high-concentration organic waste gas and convert it into harmless $\mathrm{CO} 2$ and $\mathrm{H} 2 \mathrm{O}$, it also has high requirements for catalysts, and secondary pollutants such as VOCs will also be generated in the process. Therefore, there are potential safety hazards during exhaust gas treatment. For another example, water heavy metal pollution is the key and difficult point in the treatment of water pollution in my country, and the coating process will generate a large amount of coating wastewater, which contains pollutants such as resins, surfactants, heavy metal ions, and pigments. The problems of complex composition, high concentration, and poor biodegradability of paint spray wastewater have brought certain difficulties to related wastewater treatment. Studies have shown that after the heavy metals in painting wastewater enter the soil, they will be adsorbed by colloids and organic matter, thereby accumulating and accumulating in the soil, and then being absorbed by groundwater and animals and plants to transfer, and finally accumulating in the human body, causing cancer and genetic mutations. And the high concentration of nitrogen and phosphorus in the coating wastewater will make the water body eutrophication and bring harm to the fishery and aquaculture industry. Therefore, in order to alleviate the environmental pressure and actively adjust the development ideas of the coating process, this paper uses an industrial metabolic analysis method to analyse the material metabolism process of the production line based on a certain coating production line, and explores the way of green optimization based on the results of the analysis.

\section{Industrial metabolism analysis of a painting production line}

\subsection{Method introduction}

The concept of industrial metabolism is similar to the metabolism in biology ${ }^{[1]}$. It was first proposed by Ayres and others based on the study of the impact of raw materials and energy flows on the environment. They believed that industrial metabolism is the transformation of raw materials and energy into final products and The general term for a series of interrelated material changes in the waste process. Its theoretical basis is the law of conservation of mass. According to the law of

\footnotetext{
* Corresponding author: 916060457@qq.com
} 
conservation of mass, products and waste produced through human production activities, even if they no longer have value, will not immediately disappear from the earth, and will still be in a certain form of material. Exist for a while. Industrial metabolism analysis aims to reveal the quantity and scale of substances in the operation of economic activities and the flow and storage conditions of all substances in the entire industrial activity ${ }^{[2]}$. Through industrial metabolism analysis, we can understand the operating mechanism of industrial activities as a whole, recognize the history and process of pollution, find the problem, and take targeted measures ${ }^{[3]}$. Therefore, industrial metabolism can be used to track the flow of certain pollutants, certain groups of substances (such as heavy metals), certain substance components (C, $\mathrm{S}$ ), and certain products (orange juice, electronic chips). Its method steps are as follows: collect various material data related to production; distinguish input and output materials, and convert intermediate materials in the input link into natural resources; convert the measurement unit of each material into a unified quality unit (such as KWH of electricity is converted into t); Summarize the input resources, recycling resources and output resources (products, by-products, waste products) to form a material balance sheet; finally calculate the relevant resource efficiency, energy efficiency and environmental efficiency.

\subsection{Process flow of painting production line}

The wind power gearbox is an important mechanical component of a wind power generator. Its main function is to convert the power generated by the wind into a certain speed to achieve the purpose of generating electricity. Because of its long-term exposure to wind outlets such as mountains, wilderness, islands, etc., it is affected by extreme heat and cold and extreme temperature differences throughout the year. Therefore, surface anticorrosion and corrosion prevention are an important part of the production process. Therefore, this paper selects a certain wind power gearbox coating production line as the research object, and conducts industrial metabolism analysis on it. According to the data, the paints and cleaners used in the coating production line are mainly organic solvents, so the process flow is: hoist the gear box into the feeding area-clean it-carry out primer napping-then manual or high pressure Water gun cleaningenter the waiting area for package protection-enter the intermediate room for pre-coating and spray the intermediate paint-enter the drying room to dry-enter the strong cooling room and cool to 40 degrees-polish the intermediate paint-enter the top paint room for precoating, Spraying the top coat-then enter the top coat drying room for drying-finally hoist the gear box to the unloading area. The details are shown in Figure 1.

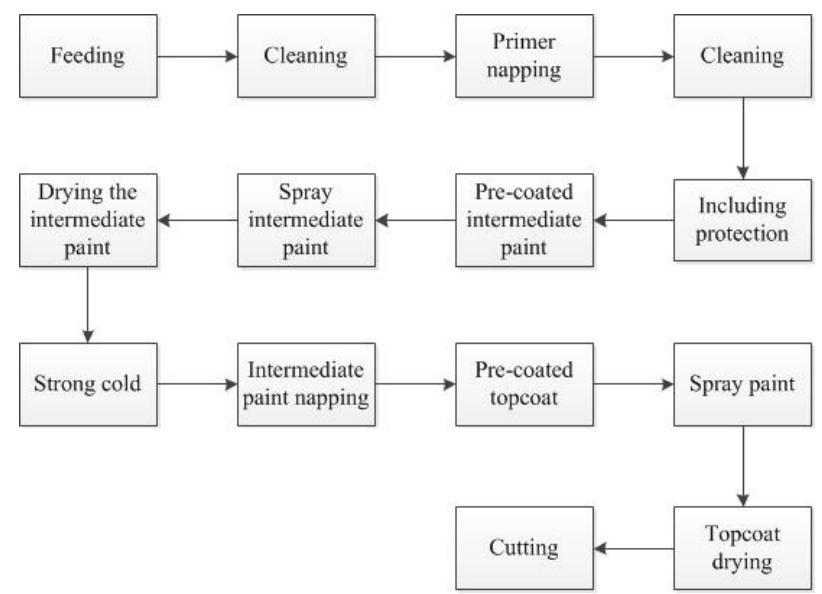

Fig. 1. Wind power gearbox coating production line process flow

\subsection{Material balance calculation}

According to the data, the input party mainly includes $700 \mathrm{t}$ of steam, 1993t of fresh water, 8t of cleaning agent and $69.4 \mathrm{t}$ of paint. The metabolic flow relationship is described and drawn according to the process flow. The result is shown in Figure 2.

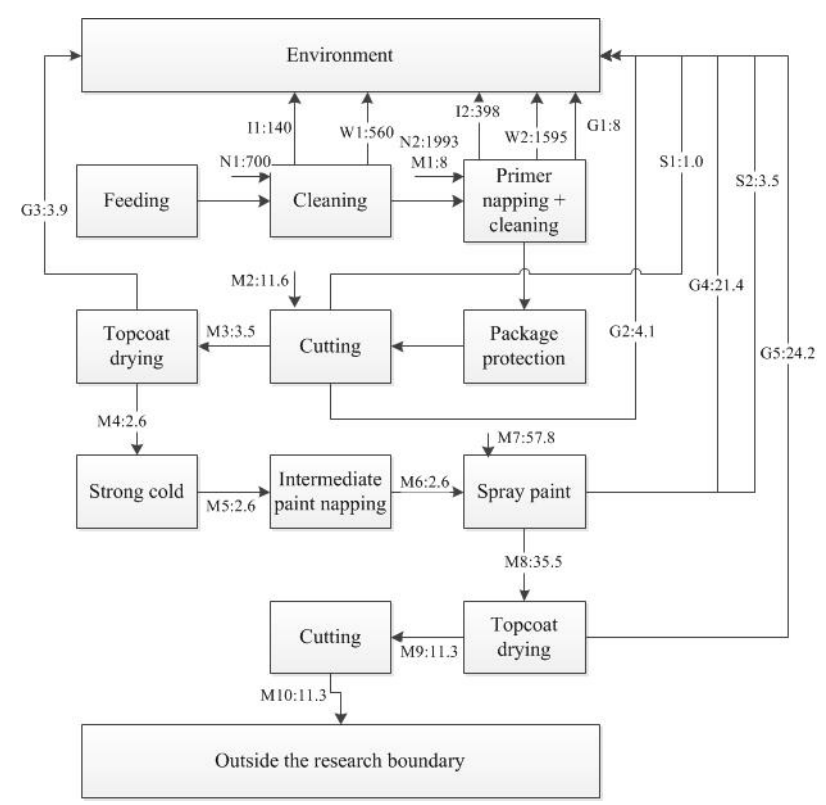

Fig. 2. Material metabolism and flow of coating production line

Among them, $\mathrm{Ni}(\mathrm{i}=1,2)$ represents the input of steam and fresh water; $\mathrm{Mj}(\mathrm{j}=1, \ldots, 10)$ represents the flow of raw materials and materials; Ii $(i=1,2)$ represents the process loss of water, mainly Dissipation occurs in the form of water vapour; Wi $(i=1,2)$ represents process waste water; $\mathrm{Gj}(\mathrm{j}=1, \ldots, 5)$ represents process waste gas; Si $(i=1,2)$ represents process solid waste. During the process, paint spraying and drying will generate organic gas. Among them, only $50 \%$ of the paint will adhere to the work piece during spraying, $20 \%$ will settle as solid waste due to inability to adhere, and the remaining $30 \%$ will become exhaust gas. The final output products mainly include $61.6 \mathrm{t}$ of waste gas, $2155 \mathrm{t}$ of waste water, $4.5 \mathrm{t}$ of solid waste (liquid) and $11.3 \mathrm{t}$ of paint on the work piece, 
plus 538t of lost water, which meets the balance of material balance as a whole, as shown in Table 1 .

Table 1. Material balance sheet of coating production line

\begin{tabular}{|c|c|c|c|}
\hline \multicolumn{2}{|c|}{ Input } & \multicolumn{2}{|c|}{ Output } \\
\hline $\begin{array}{c}\text { Material } \\
\text { name }\end{array}$ & $\begin{array}{l}\text { Quantity } \\
(\mathrm{t})\end{array}$ & $\begin{array}{c}\text { Material } \\
\text { name }\end{array}$ & $\begin{array}{c}\text { Quantity } \\
(\mathrm{t})\end{array}$ \\
\hline Steam & 700 & Exhaust & 61.6 \\
\hline Fresh Water & 1993 & Waste Water & 2155 \\
\hline Detergent & 8 & $\begin{array}{l}\text { Solid Waste } \\
\text { (liquid) }\end{array}$ & 4.5 \\
\hline \multirow[t]{2}{*}{ Paint } & 69.4 & $\begin{array}{c}\text { Loss of } \\
\text { water }\end{array}$ & 538 \\
\hline & & $\begin{array}{c}\text { Paint on the } \\
\text { workpiece }\end{array}$ & 11.3 \\
\hline Total & 2770.4 & Total & 2770.4 \\
\hline
\end{tabular}

\subsection{Analysis of Industrial Metabolism Results}

According to the material balance sheet of the coating production line, we can see that a total of 2770.4 tons of substances have been input, but only 11.3 tons of paint can be effectively applied to the work piece, and the total amount of unused "metabolic waste" has reached 2213.1 tons, of which 2,155 tons of waste water, 61.6 tons of waste gas, 4.5 tons of solid waste (liquid), and 538 tons of water were lost by evaporation. Here, $100 \%$ of the cleaning agent and $77 \%$ of the paint are converted into exhaust gas.

In order to evaluate metabolic efficiency, use resource efficiency and environmental efficiency to evaluate, the specific formula is as follows:

$$
\begin{gathered}
R E=P O / R C \\
E E=P O / W O
\end{gathered}
$$

Among them, (1) is the calculation formula of resource efficiency, RE is the resource efficiency, $\mathrm{PO}$ is the output product volume and $\mathrm{RC}$ is the resource consumption; (2) is the calculation formula of the environmental efficiency, $\mathrm{EE}$ is the environmental efficiency, WO is the waste discharge the amount.

Through calculations, the resource efficiency of the coating production line is $0.4 \%$, and the environmental efficiency is $0.51 \%$, indicating that there is a serious waste of resources and a large amount of "metabolic waste" cannot be effectively recycled and used, resulting in a great environment pressure.

Through in-depth analysis of the coating production line, it is known that because the coating production line uses a more traditional spraying operation method, the effect of the paint rate of the work piece is not ideal, and more paint slag is produced at the same time. In addition, because the paint it uses is a solvent-based paint, the VOC content of the paint is relatively high, and its use is currently strictly restricted, which will also increase the cost of waste gas treatment. Highly volatile paints and cleaning agents are not only the main source of exhaust emissions, but also the crux of the difficulty in handling terminal telomeres.

\section{The green optimization approach of a coating production line}

In response to the above problems, we will combine the input and output of the production line to propose several green optimization approaches from the perspectives of cleaner production, circular economy and ecological industrial parks. The main idea of cleaner production is to apply holistic prevention strategies in the production process, products and services to increase ecological efficiency and reduce human and environmental risks ${ }^{[4]}$. Combined with the coating production line in this article, it is necessary to save raw materials and energy in the production process, eliminate toxic raw materials, reduce the quantity and toxicity of all wastes, and achieve waste reduction, recycling and harmlessness. The essential feature of circular economy and traditional economy is that the concept of "waste" is different. Traditional economy is a linear model of "resources-products-waste", and circular economy is a circular model of "resourcesproducts-renewable resources-products". Recycle waste to realize sustainable economic development. From the perspective of circular economy, the links between production lines or between enterprises should be established, and waste from other enterprises should be used as resources into the coating production line, and waste from the production line should be used as resources into other enterprises. Eco-industrial park is a new type of industrial park designed and established based on the requirements of cleaner production, the concept of circular economy and the principles of industrial ecology. It connects different factories or enterprises through logistics or energy flow transmission, forming an industrial symbiosis combination of sharing resources and exchanging by-products, making waste or by-products of one factory the raw materials or energy of another factory, simulating natural systems, Establish a "producerconsumer-decomposer" cycle path in the industrial system, seeking material closed-loop recycling, multi-level utilization of quantities, and minimization of waste generation $^{[5]}$.

\subsection{Use paint with low VOC content}

The replacement of paint is not as simple as direct replacement, but a variety of factors must be considered, such as: whether the coating layer meets the product's use environment, whether it meets the life requirements, whether the current process conditions can be applied, etc. For this reason, various coatings need to be analysed and considered. This article selects the common types of coatings on the market, and their characteristics and requirements are shown in Table 2.

\begin{tabular}{|c|c|c|c|c|c|c|}
\hline Coating & VOC & $\begin{array}{l}\text { Coating } \\
\text { Quality }\end{array}$ & $\begin{array}{c}\text { Overall } \\
\text { Costs }\end{array}$ & $\begin{array}{c}\text { Energy } \\
\text { Consumption }\end{array}$ & investment Cost & Difficulty \\
\hline Solvent type & High & Better & Lower & High & General & General \\
\hline Water-based paint & Low & Good & Higher & High & Higher & Harder \\
\hline
\end{tabular}

Table 2 Qualitative analysis of various low VOC coatings 


$\begin{array}{clllllc}\text { Powder coating } & \text { Low } & \text { Good } & \text { Lower } & \text { High } & \begin{array}{c}\text { Newly built } \\ \text { higher }\end{array} & \text { Harder } \\ \text { High solids coating } & \text { High } & \text { Better } & \text { Higher } & \text { High } & \text { General } & \text { General } \\ \text { UV coating } & \text { Low } & \text { Better } & \text { Lower } & \text { Low } & \text { Newily built } & \text { Harder } \\ \text { higher } & \text { Saving } & \text { Easy } \\ \begin{array}{c}\text { Aspartame Polyuria } \\ \text { Coating }\end{array} & \text { Low } & \text { Better } & \text { Lowest } & \text { Low } & \text { S } & \end{array}$

From the above point of view, Aspartame polyuria coating is the most suitable. On the one hand, the topcoat is a two-coat system, which is mainly used for heavy-duty coating of steel structures. On the other hand, it does not need to modify the original process of the production line, and it can also save the primer and topcoat drying room and reduce The input cost of the process. And it fully complies with VOC emission standards, so there is no need to treat VOC exhaust gas. So on the whole, Aston polyuria coating can not only meet the harmless requirements of raw material input, but also reduce waste discharge, and has the lowest cost and is easy to implement. Therefore, Aston polyuria coating should be selected for the coating production line.

\subsection{Establish a wastewater treatment process in conjunction with the automotive industry}

Because coating wastewater contains complex components such as degreasing wastewater, phosphating wastewater, electrophoresis wastewater, and spraying wastewater, it is difficult to treat it through simple steps. For companies, it is too expensive to build a coating wastewater treatment process in order to treat wastewater. Therefore, we can learn from the practices of companies around the Rhine in Germany and establish a joint venture sewage treatment plant. In this regard, it can be jointly established with automobile manufacturing companies, and the automobile manufacturing industry is one of the main sources of coating wastewater. The process includes: pre-treating the wastewater to reduce the $\mathrm{Ni2}+$ concentration in the phosphating wastewater to $0.4 \mathrm{mg} / \mathrm{L}$, and then mixing the pre-treated degreasing wastewater, electrophoresis wastewater and spraying wastewater, first performing biochemical treatment, and then physicochemical After treatment, the final water quality will reach the standard of cleanliness and greening, and it can even be reused as an input part.

\subsection{Establish a profit-oriented industrial symbiosis relationship with thermal power plants}

Partially profitable industrial symbiosis refers to the symbiosis system that is beneficial to one party, but neither suffers nor directly gains or gains little benefit to the other party in the symbiosis system. For thermal power plants, it can generate too much waste heat and steam, which can not only provide heat as energy for the coating production line, but also provide a large amount of steam as its input raw material. This can save raw materials and energy.

\section{Conclusion}

This article analyses the industrial metabolism of a coating production line, which not only reveals the quantity and scale of the production line, but also reveals its flow pattern in the entire industrial activity, and obtains the resource efficiency and environmental efficiency. Based on this, the current problems of the production line and the ins and outs of "metabolic waste" can be further analysed, so that pollution prevention measures can be implemented in a targeted manner.

\section{References}

1. A.M. Martín, M. Marcos, F. Aguayo, J.R. Lama. Smart Industrial Metabolism: a literature review and future directions. Procedia Manufacturing, 13,2017.

2. T.J. Dai. Application of industrial metabolism analysis method in enterprise energy conservation and emission reduction. Resource science,31,04, 2009.

3. F. Han, F. Yu, Z.J Cui. Industrial metabolism of copper and sulfur in a copper-specific eco-industrial park in China. Journal of Cleaner Production, 133,2016.

4. Y.H. Mugahed Amran, R. Alyousef, H. Alabduljabbar, M. El-Zeadani. Clean production and properties of geopolymer concrete; A review. Journal of Cleaner Production, 251,2020.

5. C. Castiglione, A. Alfieri. Supply chain and ecoindustrial park concurrent design. IFAC PapersOnLine,52,13,2019. 